\title{
Antagonistic Effect of Pseudomonas sp. CMI-1 on Foodborne Pathogenic Listeria monocytogenes
}

\author{
Ágnes Belák* and Anna Maráz \\ Department of Microbiology and Biotechnology, Faculty of Food Science, \\ Corvinus University of Budapest, Somlói út 14-16, HU-1118 Budapest, Hungary
}

Received: May 20, 2014

Accepted: January 26, 2015

\begin{abstract}
Summary
Bacterial isolates derived from food or raw food materials of animal origin were screened for potential antagonistic activity against foodborne pathogenic Listeria monocytogenes. Using the agar spot method, ten out of the 94 tested bacteria showed antilisterial activity. All of the antagonistic isolates identified by sequence analysis as strains of the genus Pseudomonas were able to inhibit the growth of all the examined Listeria species including the ruminal pathogenic L. ivanovii and the opportunistic human pathogenic L. innocua. Pseudomonas sp. CMI-1 had the highest inhibitory effect on the growth of different Listeria strains. Co-culturing studies revealed that the inhibition of $L$. monocytogenes could not be achieved efficiently. Although the population of the Pseudomonas sp. CMI-1 strain increased by up to 10 orders of magnitude during 2 days of culturing period at $20{ }^{\circ} \mathrm{C}$ in the presence of L. monocytogenes, the cell count of the pathogen also increased by approx. 6 orders of magnitude. At the same time, appropriate inhibition of cell-free supernatants generated from 6-day-old cultures of Pseudomonas sp. CMI-1 was observed. The inhibitory compound of this antagonistic strain is presumably a chromopeptide siderophore, whose activity and production can be affected by iron supplementation, and which had an absorption maximum typical of siderophores of fluorescent Pseudomonas species. Production of the antilisterial substance was influenced by the oxygen concentration, as in static cultures the concentration of the siderophore was higher than in shake flask cultures.
\end{abstract}

Key words: antagonistic bacteria, Listeria monocytogenes, siderophore, fluorescent Pseudomonas sp.

\section{Introduction}

Foodborne pathogenic bacteria can cause serious illnesses via their growth or toxin production, thus leading to significant health problems of consumers. Listeria monocytogenes is frequently transferred by consumption of contaminated food and beverages, and is an important causative agent of foodborne diseases; therefore, inhibition or elimination of this pathogenic bacterium is an essential task for food producers. L. monocytogenes can be found in raw and processed foods that are contaminated during and/or after processing.

Although the Listeria genus comprises fifteen species, L. monocytogenes is the causative agent of human listerio- sis almost exclusively. The number of foodborne cases caused by L. monocytogenes in 2012 in the European Union was 1642 including 13 in Hungary (1).

Various microorganisms are able to inhibit pathogenic microorganisms by overgrowing them or producing antibiotic metabolites (2). The native microbiota of food have the ability to inhibit the contaminating foodborne pathogens, hence these microorganisms can prevent the growth of pathogenic bacteria by different control mechanisms (predation, competitive exclusion, production of antimicrobial metabolites or quorum sensing) $(3,4)$. Therefore, the application of specific bacteria isolated from foods or raw materials for the inhibition of pathogens can 
be promising in the food industry from a safety perspective. These microorganisms have the advantage of being part of the food natural microbiota, thus they can easily colonise the food and inhibit the pathogens when present in appropriate numbers (3). Inhibition of several foodborne pathogens can also be achieved by the application of bacteriophages (5), and in the last few years virulent bacteriophages have been effectively used for the inhibition of L. monocytogenes $(6,7)$.

The spoilage process of milk, fresh meat and other protein-rich raw materials represents a characteristic interaction of different microorganisms when competition of saprophytic and pathogenic bacteria for the available nutrients results in the succession of populations comprising different species. Different antagonistic bacteria have already been isolated from natural or spoiling microbiota of foods or raw materials $(3,8,9)$. Among the inhibitory bacteria several have been identified as species of Pseudomonas, and they exhibited pathogen inhibitory features (9-11).

The objective of this research is to determine the inhibitory potential of bacteria isolated from food and raw materials of animal origin against foodborne pathogenic L. monocytogenes. After performing the screening tests we focused mainly on a Pseudomonas isolate, as this bacterium showed significant inhibitory activity against not only L. monocytogenes, but other non-monocytogenes Listeria species.

\section{Materials and Methods}

\section{Bacterial strains}

Bacteria tested for inhibitory effect had been previously isolated from different processed foods or raw food materials of animal origin: among 94 isolates, 61 originated from chilled poultry meat, 9 from chilled fish, 14 from milk and 10 from liquid egg. They were maintained on peptone glucose yeast extract (PGY) agar slants (containing in $\mathrm{g} / \mathrm{L}$ : peptone 5 , glucose 1 , yeast extract 2.5 and bacteriological agar 15 ) at $5{ }^{\circ} \mathrm{C}$. Different strains of L. monocytogenes, L. innocua and L. ivanovii ssp. ivanovii (Table 1) were used for testing the antagonistic effect of the bacterial isolates.

\section{Screening of bacteria for antilisterial activity}

Ninety-four bacterial isolates were screened for the ability to inhibit L. monocytogenes CCM 4699 using a spot method as described below. L. monocytogenes was cultured on tryptone soya (TS) agar plate at $37^{\circ} \mathrm{C}$ for $18 \mathrm{~h}$, and a cellular suspension was prepared in sterile distilled water. The absorbance of the suspension was adjusted to 0.5 at $600 \mathrm{~nm}$, which corresponds to approx. $10^{9} \mathrm{CFU} / \mathrm{mL}$. A tenfold serial dilution was made and $1 \mathrm{~mL}$ of the dilutions in the range of $10^{-2}-10^{-6}$ was massively inoculated onto TS and PGY agar plates. After drying the plates, 10 $\mu \mathrm{L}$ of cell suspensions (containing approx. $10^{6}$ cells of the overnight cultures) were dropped onto the agar surface. The plates were incubated at $5,10,20,25,30$ and $37^{\circ} \mathrm{C}$ for 6 days. Growth inhibition was detected by formation of clearing zones around macrocolonies of the tested iso-
Table 1. List of Listeria strains used for the analysis of the antagonistic effect of bacterial isolates

\begin{tabular}{lll}
\hline Code & Species & Characteristics \\
\hline CCM & $\begin{array}{l}\text { Listeria } \\
\text { monocytogenes }\end{array}$ & $\begin{array}{l}\text { Reference strain, } \\
\text { serovar 4d }\end{array}$ \\
$\mathrm{H} 3$ & $\begin{array}{l}\text { Listeria } \\
\text { monocytogenes }\end{array}$ & Meat isolate \\
Listeria & Cheese isolate \\
monocytogenes & $\begin{array}{l}\text { Listeria } \\
\text { monocytogenes }\end{array}$ & Cheese isolate \\
$\mathrm{L} 23$ & $\begin{array}{l}\text { Listeria } \\
\text { monocytogenes }\end{array}$ & Unknown origin \\
$\mathrm{T} 2$ & $\begin{array}{l}\text { Listeria } \\
\text { monocytogenes }\end{array}$ & Unknown origin \\
$\mathrm{P} 1$ & $\begin{array}{l}\text { Listeria } \\
\text { innocua }\end{array}$ & $\begin{array}{l}\text { Type strain, } \\
\text { serovar 6a }\end{array}$ \\
$\mathrm{CCM}$ & $\begin{array}{l}\text { Listeria ivanovii } \\
\text { ssp. ivanovii }\end{array}$ & $\begin{array}{l}\text { Type strain, } \\
\text { serovar 5 }\end{array}$ \\
$\mathrm{CCM}$ & $\mathrm{C} 6)$ & \\
$5884^{\mathrm{T}}(\mathrm{C} 7)$ & S &
\end{tabular}

$\mathrm{CCM}=$ Czech Collection of Microorganisms

(Brno, Czech Republic)

lates. For determination of the optimal antagonistic/ pathogenic cell ratio, the selected inhibitory strains were applied in the range of $10^{1}-10^{7}$ cells $/ \mathrm{mL}$ during co-culturing on TS and PGY agar plates.

All the bacterial isolates exhibiting inhibitory effect on L. monocytogenes CCM 4699 were further tested against five other L. monocytogenes and two non-monocytogenes Listeria strains (Table 1) by the spot method.

\section{Determination of the antagonistic effect of the selected} bacterial isolates in culture broth

Co-culturing studies using TS and PGY broths were carried out in static and shake flask cultures. Overnight cells of L. monocytogenes CCM 4699 and the selected bacterial strains were suspended in sterile distilled water and the absorbance was adjusted to 0.5 at $600 \mathrm{~nm}$. After preparing tenfold serial dilutions, the culture media were inoculated with the cells of pathogenic and antagonistic bacteria in volume ratios of 1:1, 1:10, 1:100 and 1:1000, respectively. The flasks were incubated for 2 days at $20^{\circ} \mathrm{C}$ under shaking (either at 140 or $180 \mathrm{rpm}$ ) and static conditions. Samples were taken after 24 and 48 h of incubation, and cell counts were determined by the spread plate method using PGY and Listeria selective COMPASS ${ }^{\circledR}$ agar (Biokar Diagnostics, Beauvais, France) plates.

\section{Antagonistic effect of cell-free supernatants on the growth of L. monocytogenes}

Isolates showing significant antagonistic activity against L. monocytogenes were further studied for the production of extracellular inhibitory substances using the agar diffusion technique, as well as microplate cultures. Overnight cultures of the selected isolates were produced at 20,25 and $30^{\circ} \mathrm{C}$, and after separating the cells from the culture medium by centrifugation (10 976 $\times g, 15 \mathrm{~min})$, the supernatants were removed and filtered through $0.2-\mu \mathrm{m}$ 
pore size membrane filters. For the agar diffusion technique, the L. monocytogenes CCM 4699 was inoculated on the surface of TS and PGY agar plates at a final count of about $10^{4} \mathrm{CFU} / \mathrm{mL}$ and allowed to dry at room temperature. Wells $(7 \mathrm{~mm})$ were cut in the inoculated agar using a sterile metal cork borer, and filled with $100 \mu \mathrm{L}$ of the supernatant. The plates were left at $5-10{ }^{\circ} \mathrm{C}$ for $2 \mathrm{~h}$ to allow diffusion of the compounds from the tested supernatants into the agar media, and then incubated for $24-48 \mathrm{~h}$ at 20 ${ }^{\circ} \mathrm{C}$. Absence or presence of any inhibitory zone was recorded.

Effect of the inhibitory substances on $10^{6}$ of L. monocytogenes CCM 4699 cells was tested by measuring the growth in microplate cultures using a Multiskan Ascent (Thermo Electron Corporation, Thermo Fisher Scientific, Waltham, MA, USA) instrument. Wells of the plates were filled with $300 \mu \mathrm{L}$ of liquid consisting of $75 \mu \mathrm{L}$ of fourfold strength culture broth, $75 \mu \mathrm{L}$ of L. monocytogenes cell suspension and cell-free supernatants of the test strain in four different $(150,100,50$ and $25 \mu \mathrm{L})$ volumes. Final volumes were adjusted to $300 \mu \mathrm{L}$ by adding distilled water. The amounts of the cell-free supernatants corresponded to $1: 2,1: 3,1: 6$ and $1: 12$ dilutions. Inoculated microplates were incubated at $20{ }^{\circ} \mathrm{C}$ and the absorbance values at 595 $\mathrm{nm}$ were recorded automatically every $30 \mathrm{~min}$ during 24 $\mathrm{h}$ of cultivation. Growth curves were generated from the absorbance values $v s$. time data.

\section{Protease and heat treatments of the cell-free supernatants}

Inhibitory effect of the cell-free supernatants prepared from 1-, 3- and 6-day-old cultures of the tested bacteria incubated at $20{ }^{\circ} \mathrm{C}$ was determined after: (i) protease treatment by one of the following (in $\mu \mathrm{g} / \mathrm{mL}$ ): proteinase K (Sigma-Aldrich, St. Louis, MO, USA) 200, protease from Streptomyces griseus (Sigma) 200, trypsin from bovine pancreas (Sigma) 100 and $\alpha$-chymotrypsin from bovine pancreas (Sigma) 100 , at $37^{\circ} \mathrm{C}$ for $90 \mathrm{~min}$, and (ii) heat treatment at $95{ }^{\circ} \mathrm{C}$ for 5 and $30 \mathrm{~min}$, or at $121^{\circ} \mathrm{C}$ for $15 \mathrm{~min}$. The growth of L. monocytogenes in the presence of the cell-free supernatants was determined by Multiskan Ascent (Thermo Electron Corporation) instrument as described above.

\section{Detection of siderophore production}

Bacterial strains were cultivated in PGY and TS broths and their growth was monitored by photometric determination of cell density at $600 \mathrm{~nm}$. Cell-free supernatants were prepared from the cultures after 1, 3 and 6 days of incubation and siderophore production was determined by measuring the absorbance at $405 \mathrm{~nm}$ as described by Manninen and Mattila-Sandholm (12).

\section{Identification and characterisation of the antagonistic bacteria}

Antagonistic isolates were identified at species level by direct sequencing of the amplified rpoB gene or the $16 \mathrm{~S}$ rDNA PCR products, generated by the LAPS-LAPS27 and the $27 \mathrm{f}-1492 \mathrm{r}$ primer pairs, respectively $(13,14)$, and alignment of the generated sequences with those deposited in the GenBank was done by the application of the ClustalW program (UCD Conway Institute of Biomolecular and Biomedical Research, Dublin, Ireland).

The bacterial isolate with the highest inhibitory effect was further characterised by inoculating it onto PGY agar plates and incubating at $5,10,15,20,25,30,37$ and $45^{\circ} \mathrm{C}$ for 3 days to determine its optimal growth temperature. The isolate was also inoculated onto Cetrimid agar (Merck, Darmstadt, Germany), Pseudomonas Agar F (corresponds to King B) and Pseudomonas Agar P (King A) (Merck, Darmstadt, Germany), and after incubating at 20 and 25 ${ }^{\circ} \mathrm{C}$, the growth and pigmentation were recorded, while its fluorescence was detected under UV light at $365 \mathrm{~nm}$.

\section{Results and Discussion}

\section{Screening for the antagonistic effect of bacterial isolates against different Listeria species}

Altogether 94 bacterial isolates derived from different processed foods or raw materials of animal origin (chilled poultry meat or fish, milk and liquid egg) were tested for the inhibitory effect against L. monocytogenes CCM 4699 strain. For screening the inhibitory effect of the isolates, co-culturing investigations on PGY and TS agar plates were performed as described in Materials and Methods. Using different counts of L. monocytogenes CCM 4699, it was observed that the biggest clearing zones (highest inhibition) were formed when the number of the pathogen was $10^{4} \mathrm{CFU} / \mathrm{mL}$. Ten out of the 94 isolates were able to suppress the growth of L. monocytogenes CCM 4699, which originated from chilled stored poultry meat (four isolates), milk (three isolates), chilled fish (two isolates) and liquid egg ( 1 isolate) (Table 2) (15). The most efficient growth inhibition was detected at $20^{\circ} \mathrm{C}$, while the isolates belonged to either the psychrotrophic or mesophilic group of microorganisms according to their optimal growth temperatures.

Testing the antagonistic interactions of the ten inhibitory isolates with eight Listeria strains belonging to $L$. monocytogenes and non-monocytogenes Listeria species (Table 1) indicated significant differences concerning either the sensitivity or the inhibitory effects of the investigated strains, as shown in Fig. 1. Pseudomonas CMI-1 isolate showed the best inhibitory effect as it inhibited all the tested Listeria strains. Sensitivity of the L. innocua CCM $4030^{\mathrm{T}}$ strain was very similar to the majority of the investigated L. monocytogenes strains. On the other hand, L. ivanovii ssp. ivanovii CCM 5884 was the most sensitive, as all of the tested antagonistic strains were able to inhibit it, while L. monocytogenes P1 proved to be the most resistant. L. ivanovii is a ruminal pathogenic bacterium, although it has recently been found that it is a newly emerging opportunistic human pathogenic bacterium (16), therefore it can be considered as a feed- and food-contaminating target of biocontrol bacteria.

\section{Identification and characterisation of the most efficient antagonistic isolates}

The ten selected antagonistic bacteria with the best inhibitory effect were identified by sequencing either the 
Table 2. Identification of the antagonistic bacteria isolated from different raw food materials of animal origin

\begin{tabular}{llllll}
\hline Code & Origin & $\begin{array}{l}\text { Growth } \\
\text { temperature/ }{ }^{\circ} \mathrm{C}\end{array}$ & Identified species & Similarity/\% & Reference \\
\hline TM-131 & chilled-stored chicken meat & $5-30$ & P. fluorescens & $99(r p o B)$ & 15 \\
TM-161 & chilled-stored chicken meat & $5-30$ & P. fluorescens & $99(r p o B)$ & 15 \\
TS-17 & chilled-stored chicken skin & $5-30$ & P. fluorescens & $99(r p o B)$ & 15 \\
TC-4 & chilled-stored chicken & $5-30$ & P. fluorescens & $99(r p o B)$ & 15 \\
TE-8 & liquid egg & $5-30$ & P. fluorescens & $100(16 \mathrm{~S}$ rRNA) & This study \\
TMI-7 & milk & $5-37$ & P. aeruginosa & $100(16 \mathrm{~S}$ rRNA) & This study \\
TMI-9 & milk & $5-37$ & P. aeruginosa & $100(16 \mathrm{~S}$ rRNA) & This study \\
TF-14 & chilled-stored fish & $15-30$ & P. aeruginosa & $99(16 \mathrm{~S}$ rRNA) & This study \\
TF-25 & chilled-stored fish & $20-37$ & P. aeruginosa & $100(16 \mathrm{~S}$ rRNA) & This study \\
CMI-1 & milk & $5-30$ & P. frederiksbergensis or P. antarctica & 96 (rpoB) & This study \\
\hline
\end{tabular}

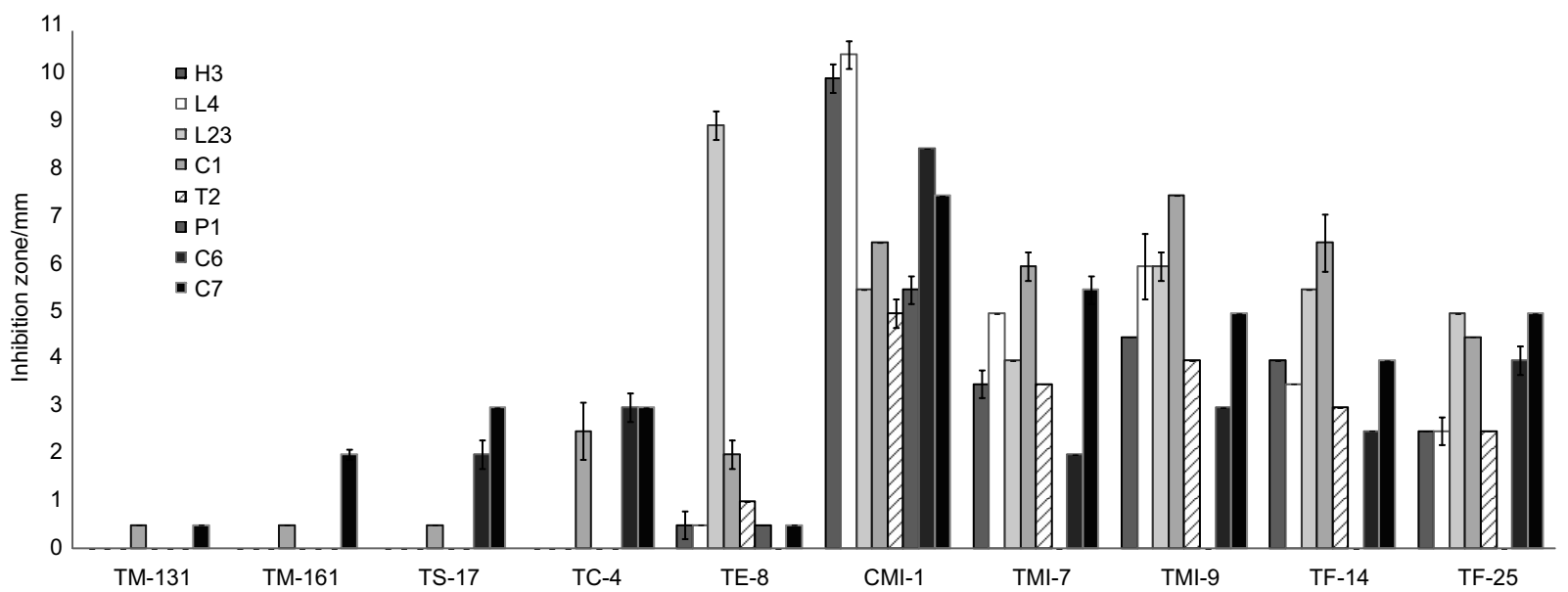

Fig. 1. Inhibition of different L. monocytogenes, L. innocua and L. ivanovii strains (Table 1) by the screened antagonistic bacterial isolates (Table 2)

rpoB or the 16S rRNA genes, which led to the conclusion that all the strains belonged to the genus Pseudomonas (Table 2). Five of them were identified as $P$. fluorescens (TM-131, TM-161, TS-17, TC-4 and TE-8), which had very weak inhibition against most of the tested Listeria strains. Four isolates with considerable and uniform spectral inhibitory activity belonged to $P$. aeruginosa (TMI-7, TMI-9, TF-14 and TF-25). It is worth mentioning that one L. monocytogenes strain (P1) was resistant against all of the four P. aeruginosa isolates, however, because of the opportunistic human pathogenic nature of this species, these isolates were excluded from further studies. Pseudomonas CMI-1 strain, which had the best inhibitory effect on the growth of Listeria strains, could not be identified with high certainty at species level. As similarity value between the aligned $r p o B$ DNA sequence of this isolate and $P$. fredericksbergensis or $P$. antarctica strains deposited in the DataBank was only $96 \%$, more detailed genotypic and phenotypic characterisation is required for the exact identification of the isolate. This is supported by the fact that, based on our investigations, this strain is different from both of the most closely sequence-related species in several characteristics. For example, the CMI-1 isolate produces fluorescent pigment(s) on King B agar property typical of neither $P$. antarctica (17) nor P. fredericksbergensis (18).

\section{Inhibition of L. monocytogenes by Pseudomonas sp. CMI-1 in co-culture experiments}

The optimum cell count of Pseudomonas sp. CMI-1 for the inhibition of L. monocytogenes L4 and CCM 4699 strains was determined by co-culturing the CMI-1 and the Listeria strains on TS and PGY agar plates. As illustrated in Fig. 2, maximum inhibition against L. monocytogenes was achieved when cell count of the CMI-1 strain was three orders of magnitude higher than that of the Listeria strains. The minimum inhibition could be detected when the difference was only one order of magnitude or less. However, minimum inhibitory cell count depended on the Listeria strain tested.

Interaction of the Pseudomonas sp. CMI-1 and L. monocytogenes CCM 4699 strains was also studied in liquid cultures by co-culturing these strains in PGY and TS broths in different ratios as described in the section Materials and Methods. Results shown in Fig. 3 indicate that increasing the ratio of CMI-1 slightly inhibits the growth of L. monocytogenes after two days of incubation. Decrease in the count of the pathogen was achieved when the cell count of Pseudomonas sp. was ten to one hundred times higher than that of L. monocytogenes. In these cases, Listeria cell number decreased by 1 or 2 orders of magnitude, while when number of the interacting bacteria was al- 

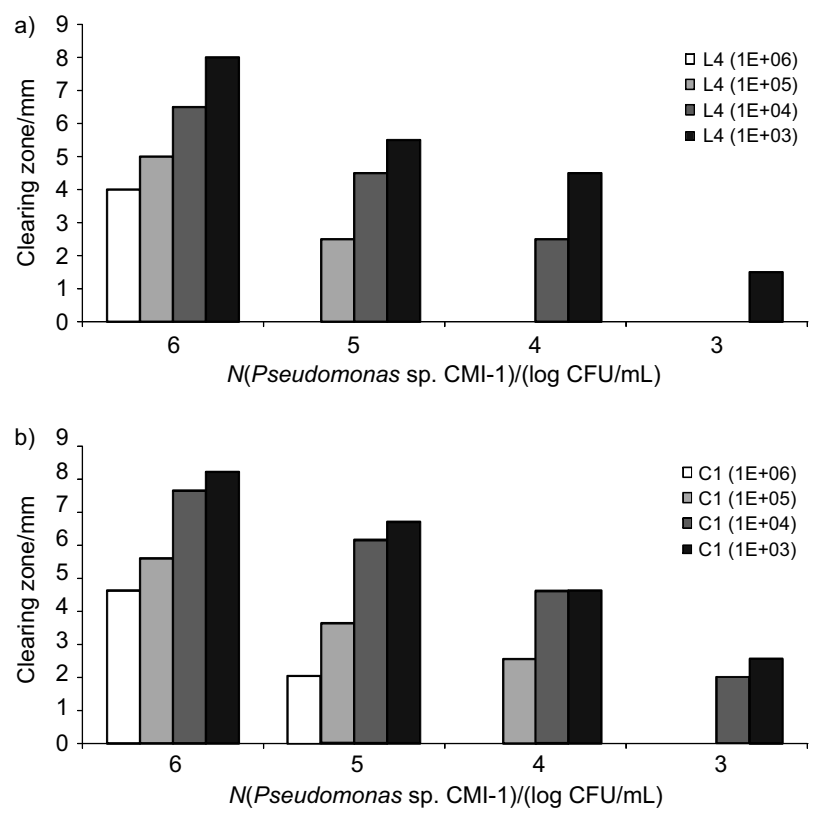

Fig. 2. Determination of the optimal L. monocytogenes and Pseudomonas sp. CMI-1 ratio for: a) L. monocytogenes L4 and b) L. monocytogenes CCM 4699 strains
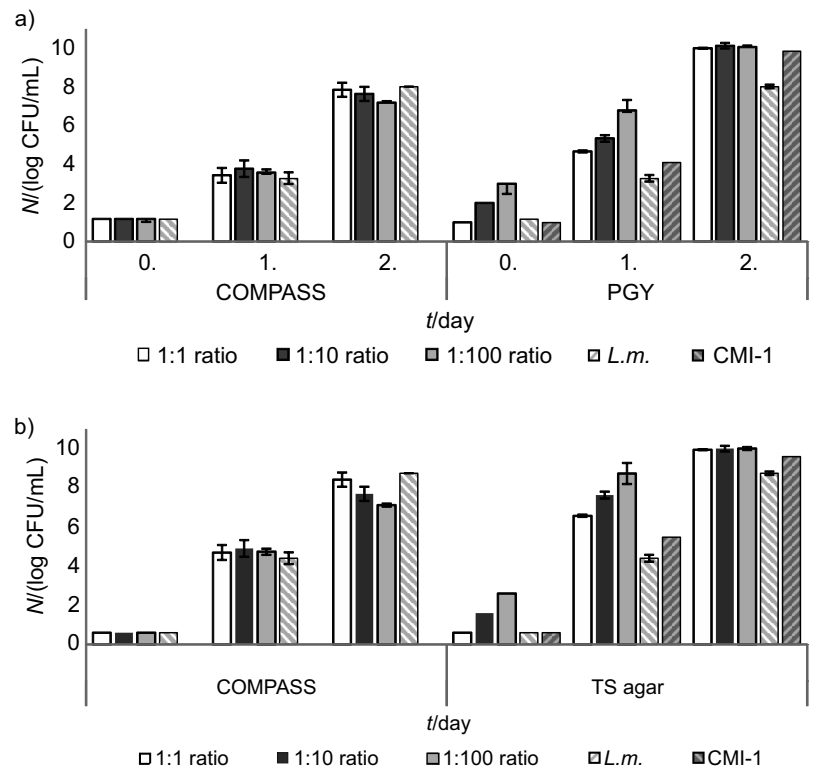

Fig. 3. Co-culturing of L. monocytogenes CCM 4699 and Pseudomonas sp. CMI-1 in: a) peptone glucose yeast (PGY) and b) tryptone soya (TS) broth using different cell ratios of pathogen to antagonist for inoculation. Total cell counts were determined using PGY or TS agar plates, while the cell number of L. monocytogenes CCM 4699 was determined using COMPASS $^{\circledR}$ L. monocytogenes selective agar

most the same, the growth rate of the pathogen was not affected. Significant differences between interactions of $L$. monocytogenes with Pseudomonas sp. CMI-1 using PGY and TS media for culturing were not observed. It can be concluded that co-culturing of Pseudomonas sp. CMI-1 and L. monocytogenes CCM 4699 in liquid broth did not result in significant growth inhibition of the pathogen. Despite the fact that the cell number of L. monocytogenes decreased in the presence of the Pseudomonas CMI-1 strain, it was not able to outcompete L. monocytogenes.

\section{Effect of cell-free supernatant on the growth of L. monocytogenes}

When the effect of the cell-free supernatant of Pseudomonas CMI-1 strain was tested on L. monocytogenes CCM 4699 by the agar well diffusion test, no formation of an inhibition zone was detected. Therefore, a more sensitive growth inhibition test was used that monitored the growth of the pathogen in the presence of cell-free supernatant. In microplate culturing experiments, where cells of the pathogen coped directly with the potential extracellular inhibitory compound(s) of the antagonist, decrease in the growth of L. monocytogenes was detected, depending on the volume of the supernatant generated after $24 \mathrm{~h}$ of incubation. Applying the highest volume (1:2 dilution) of the supernatant, growth of L. monocytogenes was inhibited by approx. $40 \%$ (Fig. 4). Moreover, differences in the inhibition were also observed if supernatants obtained from 1-, 3- and 6-day-old antagonistic cultures were applied in different ratios; 6-day-old supernatants had the strongest inhibition when applied in the highest ratio (data are not shown).

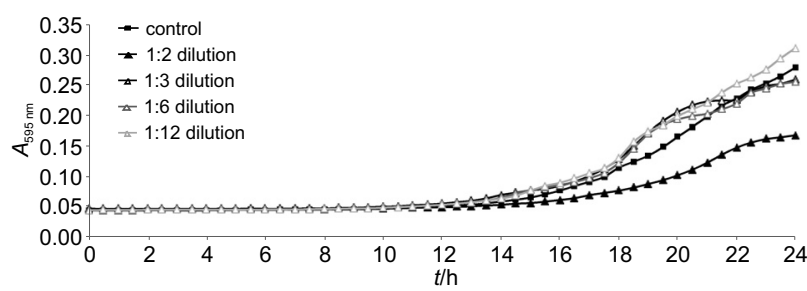

Fig. 4. Growth inhibition of L. monocytogenes CCM 4699 by different dilutions of supernatant of Pseudomonas sp. CMI-1 generated after $24 \mathrm{~h}$ of incubation

\section{Characterisation of metabolites responsible for the antagonistic effect of Pseudomonas sp. CMI-1}

As cell-free supernatants of Pseudomonas sp. CMI-1 cultivated for 6 days resulted in total growth inhibition of L. monocytogenes CCM 4699, we investigated whether the responsible extracellular metabolites could be digested by proteases of different origin or if they could be inactivated by shorter or longer heat treatments at different temperatures $\left(5\right.$ or $30 \mathrm{~min}$ at $95^{\circ} \mathrm{C}$, and $15 \mathrm{~min}$ at $121^{\circ} \mathrm{C}$ ). Fig. 5 shows that digestion of the supernatants by four differ-

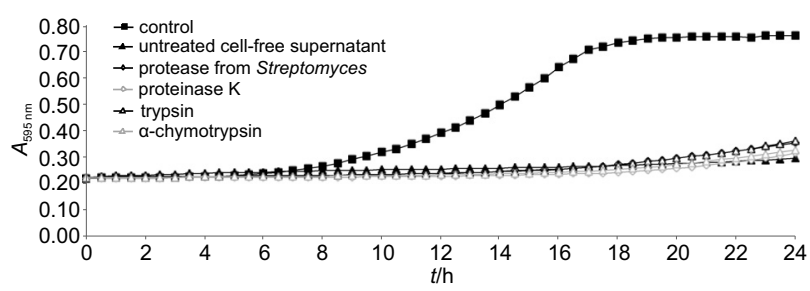

Fig. 5. Growth of L. monocytogenes CCM 4699 in the presence of protease-treated cell-free supernatants of Pseudomonas sp. CMI-1 cultivated in tryptone soya (TS) broth for 6 days 
ent proteases (protease from Streptomyces griseus, proteinase $\mathrm{K}$, trypsin and $\alpha$-chymotrypsin) did not decrease the inhibitory activity, indicating that a protein is not responsible for growth inhibition or resistance against the applied protease treatments. In the case of short $(5 \mathrm{~min})$ heat treatment at $95^{\circ} \mathrm{C}$, no change was observed in the inhibition; however, treatment of the supernatants at this temperature for $30 \mathrm{~min}$ and at increased temperature $\left(121^{\circ} \mathrm{C}\right)$ for 15 min resulted in considerable but not complete elimination of the inhibitory activity (Fig. 6). A possible explanation could be that the antilisterial compound is relatively heat stable or more than one compound is responsible for the inhibition.

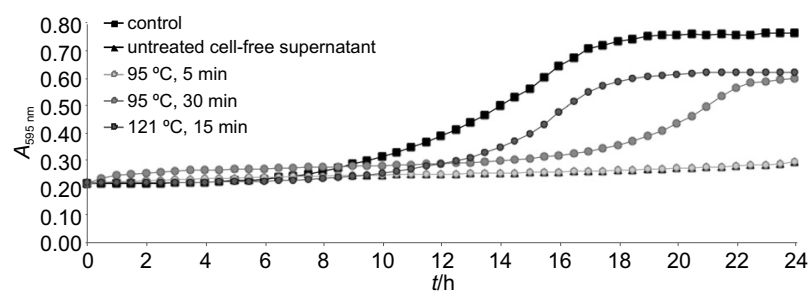

Fig. 6. Growth of L. monocytogenes CCM 4699 in the presence of heat-treated cell-free supernatants of Pseudomonas sp. CMI-1 cultivated in tryptone soya (TS) broth for 6 days

It has been frequently reported that siderophore production plays an important role in the antagonistic effect of Pseudomonas species (19), therefore, we checked for the presence of siderophore(s) in the supernatants by detecting the absorbance in the range of $400-410 \mathrm{~nm}$. A peak could always be detected at $405-410 \mathrm{~nm}$ in the antilisterial supernatants of 6-day-old static and shaken cultures, indicating the presence of one or more siderophores. Activity of the antilisterial substance of Pseudomonas sp. CMI-1 decreased after the addition of $0.1 \% \mathrm{FeCl}_{3}$, as the peak detected at $405 \mathrm{~nm}$ flattened out. Moreover, if the strain was cultured in the presence of $1 \mathrm{mM} \mathrm{FeSO}_{4}$, production of an $A_{405 \mathrm{~nm}}$ compound could not be detected (results not shown). These results indicate that one of the metabolites responsible for the antilisterial activity of Pseudomonas sp. CMI-1 can be a heat-stable compound with an absorbance maximum typical of iron-chelating substances of fluorescent Pseudomonas strains $(20,21)$. Chromopeptides, such as pyoverdine, are specific iron-binding compounds of fluorescent pseudomonads (22), seeking to deprive pathogens of iron, thus suppressing their growth (23). Chromogenic siderophores are peptides, but in our case digestion with different proteases had no effect on the activity; therefore, further analyses for determining the characteristics of the inhibitory compound(s) produced by Pseudomonas sp. CMI-1 are necessary.

Formation of siderophores is also affected by the oxygen concentration. Sabra et al. (24) observed that high concentrations of oxygen in the culture broth of $P$. aeruginosa PAO1 caused an oxidative stress to the cells which led to the reduction of the growth rate, production of exopolysaccharides (mainly alginate), and enhanced release of different proteins. However, greater pyocyanin formation was detected under microaerophilic conditions. This is in accordance with our observations in the case of Pseudomonas sp. CMI-1, which produced higher levels of the siderophore(s) in static cultures (at low oxygen concentration) than in shake flask cultures (Fig. 7). Formation of iron chelators was also influenced by the concentration of iron (25) and the presence of different organic carbon sources in the culture medium (26). Production of pyoverdine and/or pyochelin increased significantly under iron limitation, while the highest concentration of siderophores was observed in an iron-free standard succinate medium containing succinate as the sole carbon source $(25,26)$.

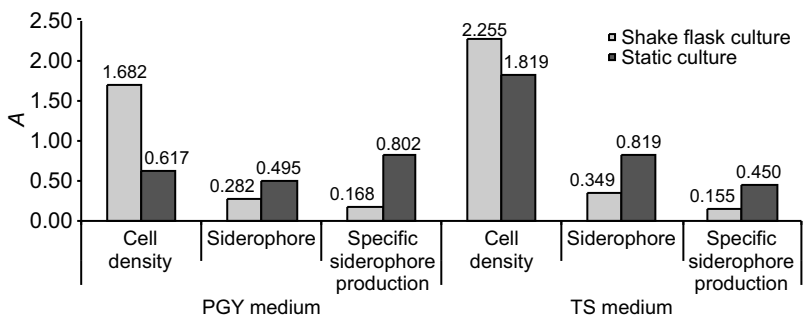

Fig. 7. Comparison of growth $\left(A_{600 \mathrm{~nm}}\right)$, siderophore production $\left(A_{405 \mathrm{~nm}}\right)$ and specific siderophore production $\left(A_{405 \mathrm{~nm}} / A_{600 \mathrm{~nm}}\right)$ by Pseudomonas sp. CMI-1 using peptone glucose yeast (PGY) and tryptone soya (TS) broths in static and shake flask cultures. The absorbance values were determined after 6 days of incubation at $20^{\circ} \mathrm{C}$

In our study, we compared the growth of cells and siderophore production in TS and PGY culture media. As it is shown in Fig. 7, TS broth supported the growth of cells better than PGY broth both in aerated and static cultures; however, the specific siderophore production, calculated as the ratio of siderophore content and cell density, was higher in PGY. This could be explained by the fact that TS broth is a more complex medium than PGY; therefore, more nutrients are available for the cells during their growth. In PGY broth the amount of accessible nutrients is lower, which can contribute to the production of stress-related substances. Moreover, the digested soya bean component contains low levels of iron, and in its presence the production of important virulence factors, such as siderophores, is partially inhibited.

When cells in PGY static culture were stressed by two rate-limiting factors (i.e. oxygen and iron availability), they responded by considerably increased siderophore production. This supports the observations of Rachid and Ahmed (26) who found that siderophore biosynthesis of Pseudomonas isolates was affected by different environmental parameters, and iron limitation was the most significant.

\section{Conclusions}

Raw food materials of animal origin can harbour bacteria that are able to inhibit the growth of foodborne pathogenic bacteria, like Listeria monocytogenes. The Pseudomonas sp. CMI-1 strain originating from milk was selected as the most promising antagonistic bacterium, which was able to inhibit all the tested pathogenic strains of the genus Listeria. Antagonistic effect of this strain was demonstrated in contact inhibition tests against L. monocytogenes; however, because direct application of the an- 
tagonistic cells for biocontrol purposes in food might lead to a spoilage-like effect, the extracellular nature of the growth inhibitory metabolites has been investigated too. Cell-free supernatants generated under different growth conditions also inhibited L. monocytogenes, and siderophores were detected as a group of potentially inhibitory compounds. However, heat- and protease-resistant compounds might also be responsible for growth decline of foodborne pathogenic L. monocytogenes. The identified and well characterised inhibitory compound(s) can be applied in food production to combat L. monocytogenes and in the agrochemical segment for the inhibition of pathogenic bacteria like L. monocytogenes. This bacterium is an ubiquitous microorganism which can be found not only in food and raw materials but also on/in plants. Earlier studies have demonstrated that pathogens may colonise the internal tissues of plants, and consumption of such contaminated vegetables can cause health hazard.

\section{Acknowledgement}

This research was supported by the European Union and the State of Hungary, co-financed by the European Social Fund in the framework of TÁMOP 4.2.4. A/-11-1-2012-0001 'National Excellence Program'.

\section{References}

1. EFSA, Analysis of the baseline survey on the prevalence of Listeria monocytogenes in certain ready-to-eat (RTE) foods in the EU, 2010-2011 Part A: Listeria monocytogenes prevalence estimates. EFSA J. 2014;12:3547. http://dx.doi.org/10.2903/j.efsa.2013.3241

2. Pal KK, McSpadden Gardener B. Biological control of plant pathogens. The Plant Health Instructor. 2006. http://dx.doi.org/10.1094/PHI-A-2006-1117-02

3. Leverentz B, Conway WS, Janisiewicz W, Abadias M, Kurtzman CP, Camp MJ. Biocontrol of the food-borne pathogens Listeria monocytogenes and Salmonella enterica serovar Poona on fresh-cut apples with naturally occurring bacterial and yeast antagonists. Appl Environ Microb. 2006;72:113540.

http://dx.doi.org/10.1128/AEM.72.2.1135-1140.2006

4. McIntyre L, Hudson JA, Billington C, Withers H. Biocontrol of foodborne bacteria: past, present and future strategies. Food New Zealand. 2007;7:25-36.

5. Goodridge LD, Bisha B. Phage-based biocontrol strategies to reduce foodborne pathogens in foods. Bacteriophage. 2011; $1: 130-7$. http://dx.doi.org/10.4161/bact.1.3.17629

6. Guenther S, Huwyler D, Richard S, Loessner MJ. Virulent bacteriophage for efficient biocontrol of Listeria monocytogenes in ready-to-eat foods. Appl Environ Microb. 2009;75: 93-100.

http://dx.doi.org/10.1128/AEM.01711-08

7. Hagens S, Loessner MJ. Bacteriophage for biocontrol of foodborne pathogens: calculations and considerations. Curr Pharm Biotechnol. 2010;11:58-68. http://dx.doi.org/10.2174/138920110790725429

8. Trias R, Bañeras L, Badosa E, Montesinos E. Bioprotection of Golden Delicious apples and Iceberg lettuce against foodborne bacterial pathogens by lactic acid bacteria. Int J Food Microbiol. 2008;123:50-60. http://dx.doi.org/10.1016/j.ijfoodmicro.2007.11.065

9. Alegre I, Viñas I, Usall J, Anguera M, Altisent R, Abadias M. Antagonistic effect of Pseudomonas graminis CPA-7 against foodborne pathogens in fresh-cut apples under simulated commercial conditions. Food Microbiol. 2013;33:139-48. http://dx.doi.org/10.1016/j.fm.2012.09.007

10. Janisiewicz WJ, Conway WS, Leverentz B. Biological control of postharvest decays of apple can prevent growth of Escherichia coli O157:H7 in apple wounds. J Food Protect. 1999;62: 1372-5.

11. Olanya OM, Ukuku DO, Annous BA, Niemira BA, Sommers $\mathrm{CH}$. Efficacy of Pseudomonas fluorescens for biocontrol of Escherichia coli O157:H7 on spinach. Int J Food Agric Environm. 2013;11:86-91.

12. Manninen M, Mattila-Sandholm T. Methods for the detection of Pseudomonas siderophores. J Microbiol Meth. 1994;19:223-34. http://dx.doi.org/10.1016/0167-7012(94)90073-6

13. Tayeb LA, Ageron E, Grimont F, Grimont PAD. Molecular phylogeny of the genus Pseudomonas based on rpoB sequences and application for the identification of isolates. Res. Microbiol. 2005;156:763-73. http://dx.doi.org/10.1016/j.resmic.2005.02.009

14. Maiwald M. Broad-range PCR for detection and identification of bacteria. In: Persing DH, Tenover FC, Versalovic J, Unger ER, Relman DA, White TJ, editors. Molecular microbiology. Washington DC, USA: ASM Press; 2004. pp. 379-90.

15. Belák Á, Kovács M, Hermann Zs, Holczman ÁN, Márta D, Cenič Stojakovič S, et al. Molecular analysis of poultry meat spoiling microbiota and heterogeneity of their proteolytic and lipolytic enzyme activities. Acta Aliment Hung. 2011; 40:3-22.

http://dx.doi.org/10.1556/AAlim.40.2011.Suppl.2

16. Guillet C, Join-Lambert O, Le Monnier A, Leclercq A, Mechaï F, Mamzer-Bruneel MF, et al. Human listeriosis caused by Listeria ivanovii. Emerg Infect Dis. 2010;16:136-8. http://dx.doi.org/10.3201/eid1601.091155

17. Reddy GSN, Matsumoto GI, Schumann P, Stackebrandt E, Shivaji S. Psychrophilic pseudomonads from Antarctica: Pseudomonas antarctica sp. nov., Pseudomonas meridiana sp. nov. and Pseudomonas proteolytica sp. nov. Int J Syst Evol Micr. 2004;54:713-9. http://dx.doi.org/10.1099/ijs.0.02827-0

18. Andersen SM, Johnsen K, Sørensen J, Nielsen P, Jacobsen CS. Pseudomonas frederiksbergensis sp. nov., isolated from soil at a coal gasification site. Int J Syst Evol Micr. 2000;50:1957-64. http://dx.doi.org/10.1099/00207713-50-6-1957

19. Laine MH, Karwoski MT, Raaska LB, Mattila-Sandholm TM. Antimicrobial activity of Pseudomonas spp. against food poisoning bacteria and moulds. Lett Appl Microbiol. 1996;22:214-8. http://dx.doi.org/10.1111/j.1472-765X.1996.tb01146.x

20. Meyer JM, Abdallah MA. The fluorescent pigment of Pseudomonas fluorescens: biosynthesis, purification and physicochemical properties. J Gen Microbiol. 1978;107:319-28. http://dx.doi.org/10.1099/00221287-107-2-319

21. Carrillo-Castañeda G, Juárez Muñoz J, Peralta-Videa JR. A spectrophotometric method to determine the siderophore production by strains of fluorescent Pseudomonas in the presence of copper and iron. Microchem J. 2005;81:35-40. http://dx.doi.org/10.1016/j.microc.2005.01.018

22. Demange P, Bateman A, Mertz C, Dell A, Piémont Y, Abdallah MA. Bacterial siderophores: structures of pyoverdins $\mathrm{Pt}$, siderophores of Pseudomonas tolaasii NCPPB 2192, and pyoverdins Pf, siderophores of Pseudomonas fluorescens CCM 2798. Identification of an unusual natural amino acid. Biochemistry. 51 1990;18:11041-51.

23. Haas D, Défago G. Biological control of soil-borne pathogens by fluorescent pseudomonads. Nat Rev Microbiol. 2005;3: 307-19. 
24. Sabra W, Kim EJ, Zeng AP. Physiological responses of Pseudomonas aeruginosa PAO1 to oxidative stress in controlled microaerobic and aerobic cultures. Microbiology. 2002;148: 3195-202.

25. Kim EJ, Sabra W, Zeng AP. Iron deficiency leads to inhibition of oxygen transfer and enhanced formation of virulence fac- tors in cultures of Pseudomonas aeruginosa PAO1. Microbiology. 2003;149:2627-34.

http://dx.doi.org/10.1099/mic.0.26276-0

26. Rachid D, Ahmed B. Effect of iron and growth inhibitors on siderophores production by Pseudomonas fluorescens. Afr J Biotechnol. 2005;4:697-702. 